\title{
JODOH DI UJUNG JEMPOL: TINDER SEBAGAI RUANG JEJARING BARU
}

\author{
Amelinda Pandu Kusumaningtyas, Azinuddin Ikram Hakim \\ ${ }^{1}$ Center for Digital Society (CFDS), Universitas Gadjah Mada \\ ${ }^{2}$ Departemen Sosiologi, Universitas Gadjah Mada
}

amelinda.pandu.k@mail.ugm.ac.id

\begin{abstract}
Tinder has become part of youth life in Indonesia and challenging the conventional and traditional way of courtship. The increasing of communication technology has an impact to change the way we communicate each other, a lifestyle, and a values in romance relationship. Tinder is one of products from the technology of media in the network societies. This case study research was conducted to understand how Tinder change Indonesian youth's courtship experience. We interviewed 3 young Tinder users from different background with diverse experience. Through this study we found five interesting findings: (1) Tinder has contributed to the decrease of parents role in courtship, (2) Tinder has simplified the conceptnof relationship, (3) Ttinder is a safe space for marginalized youth to express themselves, (4) Tinder is a part of arena for network society, and (5) Tinder is surrounded with various stigma from general public.
\end{abstract}

Keywords: Tinder, network, social change, youth

\begin{abstract}
Abstrak
Di Indonesia, kerapkali hubungan romansa masih berkutat pada nilai-nilai konvensional. Tetapi perkembangan teknologi komunikasi telah merubah perspektif lama itu menjadi persepktif baru seperti berubahnya cara berkomunikasi, gaya hidup, dan nilai-nilai dalam hubungan percintaan. Dalam hal mencari jodoh, Tinder merupakan salah satu produk dari pergeseran teknologi komunikasi yang telah menghadirkan ruang baru dalam merespon fenomena percintaan di Indonesia. Penelitian studi kasus ini dilakukan untuk memahami secara mendalam fenomena penggunaan aplikasi pencari jodoh Tinder di kalangan anak muda. Tiga orang muda dengan latar belakang dan kisah berbeda menjadi narasumber penelitian ini. Terdapat 5 (lima) temuan menarik yang didapat dari penelitian ini, yaitu: berkurangnya peran
\end{abstract}


orang tua dalam proses pemilihan jodoh di Tinder, penyederhanaan hubungan percintaan, Tinder sebagai ruang ekspresi, Tinder sebagai arena membangun jejaring sosial, dan stigma yang disematkan masyarakat umum kepada pengguna Tinder di Indonesia.

Kata Kunci: Tinder, jejaring, perubahan sosial, pemuda

\section{PENDAHULUAN}

\subsection{Latar Belakang}

Hidup di negara yang masih memegang nilai-nilai komunalitas seperti Indonesia, maka telah menjadi sebuah peraturan tak tertulis bahwa setiap insan harus membina rumah tangga lewat ikatan pernikahan guna mewujudkan keluarga yang baru. Keluarga dimaknai sebagai pranata sosial yang paling utama dan penting dalam masyarakat Indonesia, dan pernikahan adalah salah satu cara untuk melanggengkan eksistensi suatu keluarga. Pernikahan dipandang sebagai tugas bagi orang dewasa yang harus digenapi (Hurlock, 1999). Ketika seseorang telah beranjak memasuki fase dewasa muda, atau saat orang tersebut telah dianggap siap untuk menikah, ia akan mendapat tekanan dari sekitarnya untuk segera melangsungkan pernikahan. Padahal pernikahan harus melalui serangkaian proses untuk dapat terjadi. Definisi pernikahan yang kerap digunakan di Indonesia adalah definisi pernikahan yang tertera pada UndangUndang. Pernikahan dimaknai sebagai ikatan lahir batin antara seorang pria dan perempuan sebagai suami istri dengan tujuan membentuk keluarga yang bahagia dan kekal menurut Ketuhanan Yang Maha Esa (Wismanto, 2004). Dengan definisi pernikahan yang demikian maka proses yang paling dasar adalah pemilihan jodoh, sebab pernikahan haruslah terjadi antara sepasang laki-laki dan perempuan.

Manusia dapat memilih dan menemukan jodohnya dengan berbagai cara, bahkan perspektif sosiologi pun mengakomodasinya dengan adanya tujuh teori pemilihan jodoh. Namun apapun caranya terdapat kesamaan bahwa masyarakat, terlebih di masyarakat dengan kultur seperti Indonesia memilih jodoh yang sudah pernah memiliki hubungan sosial dengannya, atau setidaknya berhubungan dengan orang yang pernah memiliki hubungan sosial dengannya. Selain itu, peran orang tua bahkan keluarga secara keseluruhan juga masih sangat besar dalam pemilihan jodoh di masyarakat Indonesia. Terkadang orang tua bisa memainkan peran-peran tertentu dalam proses pencarian jodoh anaknya, misalnya saja sebagai Mak Comblang, atau perusak hubungan anaknya (Ningsih, 2015). Peran orang tua masih kentara terasa karena dalam kultur Indonesia pernikahan bukan hanya untuk kedua mempelai saja, tetapi juga untuk keluarga dari mempelai yang bersangkutan. Namun seperti cuaca yang berubah-ubah, jaman pun berubah. Nilai-nilai khas Indonesia kini harus berhadap-hadapan dengan nilai-nilai lain. Globalisasi mengaburkan sekatsekat pemisah yang memisahkan dunia 
sehingga dunia menjadi tak berbatas dan berjarak. Teknologi yang menjadi tandem setia dari globalisasi juga berandil besar dalam perubahan yang terjadi di dunia. Segala sesuatu diteknologikan, termasuk dalam urusan pencarian jodoh. Hari ini terdapat banyak aplikasi pencari jodoh yang dapat diunduh di gawai pintar dan ditujukan untuk memudahkan seseorang dalam mencari jodoh. Keberadaan aplikasi pencari jodoh yang sarat dengan nilai-nilai global memberi warna baru dalam khazanah pencarian jodoh di Indonesia.

Salah satu aplikasi pencari jodoh yang paling jamak digunakan adalah Tinder (marieclaireuk.com, 2017). Kelompok usia dewasa muda, atau yang setara dengan usia mahasiswa adalah pengguna terbesar (Kao, 2016). Temuan ini menjadi menarik mengingat pada usia-usia tersebut biasanya dipenuhi dengan tekanan-tekanan untuk segera mendapatkan pendamping sehingga Tinder menjadi salah satu rujukan favorit. Penggunaan Tinder untuk mencari jodoh mendobrak nilai-nilai yang ada di tengah masyarakat Indonesia hari ini. Yvone Alen, seorang pakar cinta kelas dunia pun mengatakan bahwa Tinder telah mengubah tatanan romansa di tengah masyarakat hari ini. Hari ini sedang terjadi sebuah transformasi besar dalam bagian hidup manusia yang berhubungan dengan kelangsungan masyarakat itu sendiri, yaitu soal pemilihan jodoh.

Membaca adanya perubahanperubahan yang terjadi, peneliti tertarik untuk menggali lebih dalam tentang aplikasi Tinder dan pencarian jodoh di kalangan anak muda. Apalagi, Tinder telah menjadi bagian dari budaya populer dan youth culture Indonesia.
Sayangnya, belum banyak yang mencoba memahami lebih lanjut tentang fenomena tersebut. Hal tersebut penting dilakukan melihat bagaimana Tinder berhasil merubah tatanan kultur pencarian jodoh, merefleksikan, serta mendefinisikan kembali kehidupan masyarakat modern di Barat. Oleh karena itu, melalui tulisan ini penulis mencoba memahami dan mengelaborasi penggunaan Tinder di kalangan muda Indonesia.

\subsection{Pemilihan Jodoh dalam Lanskap Indonesia}

Terdapat beragam satuan-satuan sosial dalam masyarakat, dan keluarga adalah salah satunya. Keluarga disebut sebagai satuan sosial paling primer dalam masyarakat karena sebagai kelompok sosial yang paling kecil, keluarga lah yang akan membentuk satuan-satuan sosial lain yang lebih besar (Burgess, 1978). Kerap kali keluarga dipandang sebagai cikal bakal terbentuknya masyarakat. Karena itu tidak mengherankan bila keluarga kerap dibahas saat mengkaji masyarakat. Dalam persepektif ilmu sosiologi dikenal pula sosiologi keluarga, kajian keluarga secara sosiologis yang sarat akan teori-teori khas sosiologis dalam memahami keluarga dan isuisu terkait di sekitarnya. Salah satu bahasan dalam sosiologi keluarga adalah soal pemilihan jodoh (Goode, 1991). Pemilihan jodoh dalam perspektif sosiologi keluarga dijelaskan melalui tujuh teori yang berbeda. Teori tersebut adalah; homogami, insting, heterogami, pertukaran, teori Reis-Wheel, filter, dan Stimulus-Value-Role.

Pemilihan jodoh secara homogami adalah pemilihan jodoh yang dilakukan dengan mempertimbangkan kesamaan- 
kesamaan yang dimiliki dengan orang lain. Kebalikan dari homogami adalah heterogami yang memilih jodoh berdasarkan dengan perbedaanperbedaan yang ada. Dalam teori insting, seseorang dikatakan memilih jodoh berdasarkan insting, atau intuisinya yang 'mengatakan' bahwa seseorang itu adalah jodoh yang tepat untuknya. Sedangkan dalam teori filter seseorang memilih jodoh dengan menekankan pada logis faktor penyaring. Faktor pertama yang disaring adalah faktor endogami, homogami, dan heterogami. Setelah seseorang telah lolos penyaringan, maka ia lah jodoh yang tepat bagi seseorang. Sedangkan dalam teori Reis-Wheel terdapat empat langkah yang dilewati dalam pemilihan jodoh. Bermula dari perjumpaan, saling membuka diri, kemudian mulai bergantung pada satu sama lain, dan timbullah cinta. Teori ReisWheel menekankan pada proses-proses yang terjadi hingga timbulnya cinta dan terpilihnya jodoh. Pakem yang sama juga terdapat dalam teori Stimulus-Value-Role. Jodoh menurut teori SVR dimulai dari ketertarikan fisik, kemudian menemukan kecocokan, dan berbagi peran bila memungkinkan hingga akhirnya menjadi jodoh bagi satu sama lain.

Berbeda dengan teori yang telah disampaikan di atas, teori pertukaran sangat menekankan pada hubungan untung-rugi. Pemilihan jodoh mempertimbangkan pada hal-hal apa saja yang dapat ditawarkan kepada satu sama lain, baik non-materi maupun aspek material. Prinsip ekonomi digunakan dalam memilih jodoh. Bila seseorang dianggap menguntungkan, maka ia akan dipilih sebagai jodoh. Teori ini diamini pula lewat pemaknaan bahwa pernikahan sejatinya adalah sebuah transaksi tanpa akhir. Meskipun terdapat banyak perbedaan dari ketujuh teori pemilihan jodoh yang dikenal dalam kajian sosiologi keluarga, namun ada intisari yang bisa diambil. Yaitu bahwa pemilihan jodoh memang bisa beragam caranya, tetapi selalu dimulai dengan hubungan langsung, atau setidaknya mengenal orang yang kenal dengan jodoh kita terlebih dahulu (Ningsih, 2015). Situasi ini pula yang terjadi di Indonesia. Umumnya seseorang memilih jodoh berdasarkan dengan hubungan sosial yang telah ia miliki dengan orang tersebut. Bahkan dalam tradisi perjodohan di Indonesia, jamaknya kedua orang tua yang hendak menjodohkan anaknya sudah saling mengenal. Mengenal di kehidupan 'nyata' menjadi sebuah keharusan dalam pemilihan jodoh di Indonesia.

\subsection{Globalisasi dan Jodoh di Ujung Jari}

Globalisasi memiliki banyak makna. Namun dalam bahasan ini peneliti memaknai globalisasi dengan definisi yang dikemukakan oleh Giddens (1999) sebagai intensifikasi hubungan masyarakat di seluruh dunia yang mengaitkan dan menghubungkan seluruh daerah sehingga kejadian lokal dapat terbentuk dari peristiwa yang terjadi bermil-mil jaraknya dan sebaliknya. Pemaknaan globalisasi yang demikian sangat relevan saat digunakan untuk melihat keberadaan Tinder di Indonesia. Ketiadaan sekat-sekat yang memisahkan manusia-manusia dunia membuat kebudayaan satu dengan yang lain melebur, termasuk dalam urusan pemilihan jodoh. Sebelumnya pemilihan jodoh di masyarakat Indonesia melewati cara-cara yang konvensional. Tetapi, 
dengan adanya meleburnya budaya dunia mau tidak mau hal ini harus terjadi.

Akan tetapi, keberadaan Tinder sebagai sarana baru untuk mencari jodoh tidak selamanya membawa dampak positif. Menurut penelitian yang telah dilakukan oleh Kao (2016) kemunculan Tinder telah merubah proses pencarian jodoh ditengah kaum dewasa muda. Hal-hal yang ditekankan melulu pada hal superficial, materialistik, dan tidak memiliki konsistensi. Temuan-temuan ini lah yang membuat posisi Tinder maupun aplikasi kencan serupa dalam kehidupan masyarakat dunia hari ini perlu dipertanyakan kembali. Temuan ini juga mengindikasikan bahwa tak selamanya rasa manis yang didapat dari globalisasi, sebab globalisasi sengaja maupun tak sengaja menghapuskan nilai-nilai, budaya, maupun esensi dasar dari kehidupan manusia.

Bahasan tentang Tinder kemudian menjadi semakin menarik tatkala disandingkan dengan teori Castell (2005) yang berkaitan dengan kehidupan masyarakat kontemporer saat ini menjadi relevan. Castell memaparkan bahwa kini kita tengah hidup di zaman yang dihubungkan oleh kemajuan teknologi informatika tanpa sekat. Castell memulai perdebatan diantara teknologi dan masyarakat itu bermula. Bukan paradigma terkait teknologi itu yang membentuk masyarakat, tetapi masyarakat itu sendiri yang membentuk teknologi berdasarkan kebutuhan, nilai, dan kepentingan kenapa teknologi itu harus ada. Sementara informasi teknologi itu telah menghasilkan efek sosial yang besar bagi masyarakat.

Castell (2005) meyakini adanya perubahan masif yang akan masyarakat rasakan pada tahun-tahun mendatang. Castell menjelaskan dalam pola-pola kerja yang mulanya kapital didasarkan pada etnik beralih menjadi relasional di dunia maya. Belum lagi jenis-jenis pekerjaan yang dulu menuntut pekerjaan bagi buruh-buruh industri beralih kepada pekerjaan yang mengandalkan sektor jasa. Secara tidak langsung perkembangan teknologi informasi dan kekuatan informasi itu telah menggeser norma, melahirkan gaya hidup baru, membentuk simbol-simbol baru.

Atas berubahnya sifat-sifat menuju sistem yang online karena kehadiran internet tersebut, kita mengalami kehidupan dan dimensi baru yang selanjutnya disebut oleh Castell sebagai keadaan Network Society. Keadaan sebagai sebuah tahapan transisi dari yang serba konvensional berubah ke arah sistem informasi yang saling terhubung di dalam masyarakat jejaring. (Castell and Cardaso, 2005).

Network Society merupakan term yang sederhana, seperti struktur sosial berdasarkan jejaring yang dioperasikan melalui teknologi informasi dan komunikasi, dengan basis-basis mikroelektronik dan jejaring digital yang dengan mudah memproses dan mendistribusikan informasi ke dalam kode dan angka. (Castell, 2005:7). Manusia hari ini kerap kali mengalami ketidaksadaran dalam mengonsumsi kemajuan digital komunikasi. Mereka terhubung dalam keseharian melalui koneksi internet di dalam gawai mereka, sehingga merubah hampir segala bagian lini kehidupan seperti relasi komunikasi, gaya hidup baru, dan bentuk konsumsi terhadap simbol-simbol baru. Menurut Castell, dunia yang terhubung oleh 
data-data di dalam teknologi informasi bernama internet ini mempengaruhi berbagai lini pengetahuan, ekonomi, teknologi, inovasi, produktivitas, dan kompetisi.

Itulah sebabnya Castell menyebut Network society juga sebagai bentuk transformasi sosial, dengan landasan transformasi dari komunikasi ke dalam bentuk media.

The network society is a hypersocial society, not a society of isolation. People, by and large, do not fake their identity in the Internet, except for some teenagers experimenting with their lives. People fold the technology into their lives, link up virtual reality and real virtuality, they live in various technological forms of communication, articulating them as they need it. A central feature of the network society is the transformation of the realm of communication, including the media. (Castell, 2005:11)

Salah satu output dari media teknologi komunikasi adalah media sosial. Menurut Kertamukti, et.al. (2019), media sosial adalah teknologi berbasis web yang terhubung melalui server dalam membentuk ruang komunikasi baru, setiap individu dapat melakukan aktivisme seperti membuat, menyunting, publikasi, berpromosi, mengunggah, membagi pesan, foto maupun video yang dikehendaki, dengan pengembangan aplikasi yang menghadirkan keefektifan, efisiensi, cepat, interaktif dan variatif. Lebih lanjut, Kertamukti menjelaskan implikasi dari media sosial yakni membuka ruang dalam berinteraksi antar pemilik komputer, membuka ruang berbagi offline menjadi berjejaring online, dan menciptakan praktik konsumsiproduksi pesan.

Tinder merupakan salah satu bentuk media sosial yang dapat bertukar pesan, menggugah foto, alih-alih berhenti pada tindakan saling berbagi, Tinder memiliki fungsi baru dalam merepresentasikan kondisi percintaan saat ini, terlebih dalam mencari pasangan hidup. Dalam melihat fenomena ini tentu dapat dimaknai sebagai perubahan sosial, sebagai pergeseran teknologi komunikasi yang menggeser pola-pola percintaan yang konvensional menjadi terhubung secara daring melalui aplikasi berbasis internet.

\section{METODE}

Penelitian ini menggunakan pendekatan kualitatif dengan metode penelitan studi kasus. Pendekatan kualitatif digunakan untuk dapat menjawab pertanyaan penelitian yang mengharuskan peneliti untuk melakukan eksplorasi secara mendalam terhadap permasalahan yang diteliti. Studi kasus dirasa tepat digunakan sebagai metode untuk penelitian ini karena beberapa pertimbangan. Pertama, karena rumusan masalah yang diajukan penelitian ini. Yin (1994) menjelaskan bahwa studi kasus dapat digunakan untuk menjawab pertanyaan penelitian berupa bagaimana (how) dan mengapa (why), kedua pertanyaan tersebut mengindikasikan perlunya eksplorasi terhadap permasalahan yang ingin dijawab melalui penelitian.

Kedua, dalam studi kasus perilaku subjek tidak dapat dimanipulasi sehingga dapat didapat temuan yang autentik dari fenomena yang diteliti. Penelitian mengenai Tinder dan pencarian jodoh di kalangan muda ini merupakan fenomena 
yang kontemporer. Karena alasan demikianlah peneliti menggunakan studi kasus sebagai kacamata karena menurut Yin (1994) fokus studi kasus adalah untuk meneliti fenomena-fenomena yang cukup kontemporer.

Kriteria narasumber yang penulis wawancarai dalam Penelitian ini difokuskanpadasatukriterianarasumber, yaitu kaum muda Yogyakarta yang menggunakan aplikasi Tinder. Pengumpulan data dilakukan dengan wawancara dan observasi partisipatoris. Peneliti turut menggunakan aplikasi Tinder selama kurang lebih tiga bulan guna menambah khasanah wawasan tentang Tinder. Adapun narasumber dalam penelitian ini adalah; (1) Jati, mahasiswa berusia 20 tahun; (2) Trica, mahasiswi dan pengusaha muda berusia 21 tahun; dan (3) Putra, mahasiswi berusia 22 tahun. Ketiga narasumber pemuda tersebut akan dijabarkan sebagai

\section{III.HASIL DAN PEMBAHASAN}

\subsection{Kisah Jati}

"Buat orang kayak aku yang udah sering banget jadi bahan ketawaan, Tinder itu surga banget sumpah. Kamu ngerti kan dari dulu aku kayak selalu di bully karna mukaku kayak gini, dan aku nerd, sangat ambis. Udah susah banget buatku menembus barrier itu yang bikin aku susah buat deket sama orang. Ya kamu mau bilang that $i^{\prime} m$ not that ugly tapi aku sadar diri kok kalo aku emang ga ganteng. Ga kayak itu tuh yang gampang banget dapet cewek." (Jati, 2017)
Sadar bahwa ia tak dikarunia wajah rupawan dan pribadi yang menarik, Jati memahami bahwa ia tak kan mungkin menemukan pasangan hidup. Telah berulang kali ia mencoba mendekati perempuan, tapi tak ada satupun yang mendambakannya. Tak tampan dan kutu buku, Jati masuk dalam kategori laki-laki bukan dambaan yang kerap kali dijadikan bahan lawakan di acara dagelan khas Indonesia di televisi. Jati sudah kenyang dengan penolakan namun ia lapar akan rasa cinta romantis yang belum pernah ia rasakan seumur hidupnya. Jati lelah berusaha dan ingin pasrah pada kenyataan hidup, beruntung di tengah keputusasaannya ia mengenal Tinder, aplikasi pencari jodoh yang mengubah hidupnya.

Jati mengenal Tinder di tahun keduanya berkuliah di Yogyakarta. Kala itu ada beberapa temannya yang menggunakan Tinder dan berhasil menemukan pasangan. Berkenalan dengan perempuan secara langsung adalah momok mengerikan bagi Jati yang selalu dihantui ketakutan bahwa tak ada perempuan yang mau bicara dengannya karena parasnya. Karena itu saat mengetahui perkenalan di Tinder selalu dilakukan lewat berkirim pesan singkat Jati dengan bulat memutuskan untuk menggunakan Tinder.

Berselang beberapa jam setelah Jati membuka akunnya, sudah ada belasan perempuan yang match dengannya. Untuk pertama kalinya Jati merasa didambakan oleh orang lain, kepercayaan diri yang selama ini tak ada perlahan mulai tumbuh dalam diri Jati. Berharihari Jati berkirim pesan dengan beberapa perempuan yang match dengannya. Beberapa berujung dengan kopi darat, 
sedangkan yang lainnya terlupakan dan tak ada lanjutannya. Walau begitu Jati merasa lebih bahagia ketimbang saat sebelum ia mengenal Tinder. Memang tak ada yang berlanjut menjadi pacar hingga hari ini, tapi Jati berhasil mendapatkan teman, sesuatu yang juga tak mungkin ia temukan sebelumnya.

Hasil postitf yang didapatkan membuat sulit bagi Jati untuk tidak membandingkan Tinder dengan pencarian pasangan di dunia nyata. Banyak hal yang digarisbawahi Jati sebagai perbedaan mencari pasangan di Tinder dengan di dunia nyata. Pertama, laki-laki tak melulu dipasrahi kewajiban untuk memulai perkenalan lebih dulu. Bila seorang perempuan ingin berkenalan dengan laki-laki lebih dulu maka hal tersebut adalah lumrah dan ia tidak akan dilabeli dengan label-label yang merendahkan. Hal ini dalam pandangan Jati sangat berbeda dengan proses pendekatan laki-laki dan perempuan di dunia nyata di mana perempuan besar kemungkinannya untuk mendapat label yang buruk bila memulai pendekatan terlebih dahulu:

"Waktu awal-awal masa orientasi kampus aku match sama banyak cewek. Semuanya chat. Dan itu ga aku doang lho yang ngechat duluan, ada juga yang mereka duluan yang ngechat. Biasanya kan kalo di dunia nyata harus cowok duluan nih yang mulai duluan, di Tinder engga. Dan cewek kayaknya juga ga akan dijudge kalo dia chat duluan. Dari sini nih aku ngerasa kalau ternyata aku masih desireable. Kalau biasanya aku yang harus duluan, sekarang aku yang dikejar, ya gitu lah kira-kira." (Jati, 2017)
Kedua, menurut Jati pengguna Tinder lebih terbuka ketimbang orang-orang yang telah ia temukan di dunia nyata. Selama menggunakan Tinder Jati sudah match dengan puluhan orang padahal ia tak pernah mengedit foto profilnya atau menutupi kepribadian anehnya di profil akun.Jatiselalujujursaatmendiskripsikan dirinya sehingga pengguna lain tahu betul bahwa Jati adalah seseorang yang ambisius, akademis, dan seorang grey asexual. Deskripsi yang demikian akan membuat Jati mendapat penolakan di dunia nyata, namun di Tinder ia tetap mendapatkan puluhan match dan banyak perempuan yang tertarik dengannya. Dari sinilah muncul anggapan dari Jati bahwa pengguna Tinder lebih terbuka dan menerima perbedaan-perbedaan yang ada.

"Oiya, orang-orang di Tinder tuh lebih terbuka, apalagi soal sexuality and $i$ dont know why. Aku benerbener bisa nulis siapa aku di bio-ku. Bahkan aku sampai nulis kalo aku gray asexual dan itu diterima dengan positif." (Jati, 2017)

“Enaknya lagi, aku bener-bener bisa ngetes apakah mukaku tuh laku apa engga. Kamu tau kan, aku selalu insecure dengan mukaku karena cuk aku emang jelek banget. Tau kan kalau tiap aku deket sama cewek pasti akhirnya dia milih yang lebih ganteng. Nah lewat Tinder nih aku bisa rada percaya diri karna tau kalo masih ada yang mau sama aku." (Jati, 2017)

Ketiga, hubungan di Tinder tak melulu eksklusif dengan satu orang. Pernah beberapa kali dalam satu waktu 
Jati melakukan pendekatan dengan beberapa perempuan. Kala itu tak ada rasa tidak nyaman atau bersalah yang dirasakan oleh Jati. Ia merasa bahwa hal tersebut adalah sah-sah saja. Saat hubungan tak berjalan mulus Jati tak perlu risau untuk mengakhiri, cukup berhenti berkirim pesan singkat saja maka hubungan diantara mereka usai. Tak perlu bersusah payah karena toh mereka tak akan bertemu lagi.

"Aku engga ada tanggungan apaapa. I mean aku ga perlu takut dicap PHP karna tiba-tiba menghilang pas dichat. Soalnya itu sesuatu yang normal di Tinder. Lagian kan juga ga akan ketemu atau berhubungan lagi sama orangnya, jadi ga masalah." (Jati, 2017)

Keempat, meskipun Tinder membawa banyak kemudahan dalam pencarian jodoh tetapi Tinder masih dipandang sebelah mata oleh masyarakat umum. Pengguna Tinder dipandang sebagai orang-orang yang rendah diri dan tidak bermoral. Karena itu Jati enggan mengaku menggunakan Tinder kecuali pada orang-orang terdekatnya.

"Banyak tau, aku dikatain jablay. Tapi yang ngatain bercanda gitu sih temen sendiri, belum pernah dikatain orang lain. Tapi ya emang kalo ditengah masyarakat orangorang macem aku gini distigma jablay dan gatel cuma gara-gara pake Tinder. Bitch please ini two thousand and seventeen. Sterotype kayak gini nih yang bikin aku sering uninstall Tinder dan bikin akun-akun baru" (Jati, 2017)
Kelima, walaupun Tinder ditujukan sebagai aplikasi pencarian jodoh, hubungan di Tinder memiliki kecenderungan untuk tidak didasari perasaan cinta sepenuhnya. Berdasarkan pengalaman Jati, perasaan cinta romantis yang ia rasakan hanya berlangsung sekejap dan berganti dengan perasaan cinta tapi yang tidak romantis dan kurang intim. Karenaitu pada akhirnyahubungan tersebut berakhir sebatas menjadi teman. Setelah beberapa saat menggunakan Tinder Jati tak lagi berfokus mencari pasangan, malahan fokusnya adalah mencari teman. Meskipun demikian, Jati tidak menutup kemungkinan bahwa kelak ia akan mencari istri lewat Tinder, karena baginya Tinder adalah surga yang menyajikan kemudahan.

"Kalau orang pakai Tinder cuma
baut ngewe kalo engga cari pacar
tapi kalo aku pakai ini utamanya
buat cari temen. Soal pacar ya nanti
kalau aku lagi mood cari pacar" (Jati,
2017)

"Kalau sampai besok aku masih kayak gini, of course aku bakal cari calon di Tinder. Cari yang langsung ribet, eh." (Jati, 2017)

\subsection{Kisah Trica}

Trica mengenal Tinder pertamakali di tahun 2015 melalui kakaknya. Setelah pertamakali mencoba, Trica menjadi ketagihan dan betah menggunakan Tinder. Sebab lewat Tinder ia mampu berkenalan dengan berbagai macam lakilaki, sesuatu yang belum pernah ia alami sebelumnya.

"Aku pake tinder itu tahun 2015, bulannya lupa, oh awal bulan. Jadi, 
kakakku yang ngenalin, karena waktu itu masih baru-baru nya. Trus jadi sempet ketagihan karena banyak cowok gitu lho, jadi banyak kenalan, jadi banyak tau tentang karakter cowok tu gimana aja." (Trica, 2017)

Motivasi utamanya menggunakan tinder adalah untuk cari pacar dan teman berjalan-jalan. Selama dua tahun terakhir Trica selalu berhasil mendapatkan kekasih lewat Tinder. Hubungan yang ia jalani dengan pacarnya pun tergolong lama.

"Jujur ya aku dulu buat cari pacar, aku juga pernah dapat pacar dari tinder dan itu kakak tingkat di kampus sendiri, selain itu aku juga cari temen buat jalan-jalan gitu. Aku udah beberapa kali pacaran sama orang di Tinder. Ya semuanya berjalan lama sih. Ada yang setaun juga, ada yang LDR tapi bisa awet beberapa bulan. Tapi ya gimana ya, kamu selalu punya ekspektasi lebih karna kamu belum-belum ngenal banget pasanganmu. Tapi it's okay sih" (Trica, 2017)

Meskipun berhasil menjalin hubungan beberapa kali dengan laki-laki yang ia temui di Tinder, Trica merasa bahwa ada perbedaan yang kentara saat menjalin hubungan dengan laki-laki yang ia kenal lewat Tinder. Ia mengungkapkan bahwa ketika berkenalan melalui Tinder ada ekspektasi yang lebih tinggi. Saat ia menilai seseorang hanya berdasar pada profil pengguna dan telah berekspektasi tinggi, kerap pula ekspektasi tersebut runtuh ketika ia bertemu secara langsung. Ia merasa bahwa seseorang mampu memasang "image" yang berbeda pada profil pengguna. Berbeda dengan pendekatan melalui dunia maya, pendekatan yang dilakukan secara langsung atau melalui dunia nyata lebih terkesan pasti karena ia merasa dapat melihat positif dan negatifnya secara langsung sebelum ia berekspektasi.

"Ya jelas kalau di dunia maya itu lebih pasti mereka pede, dan ekspektasinya keliatan tinggi, kadang kalo aku dah ketemu itu ekspektasinya dari aku beda gitu lho, nah pas udah ketemu itu beda di hp sama pas ketemu dan lebih sering kecewanya kalau di dunia maya daripada dunia nyata. Kalau di dunia nyata kan udah kenal langsung dan udah tahu kekurangan dan kelebihannya secara nyata. Nggak usah harus pasang impres palsu." (Trica, 2017)

Terkadang Trica enggan mengungkapkan pada orang lain bahwa ia adalah pengguna Tinder. Reaksi yang ia dapat kan saat mengungkapkan bahwa ia menggunakan Tinder beragam, tapi lebih cenderung mendapatkan reaksi yang negatif.

“Ketika aku bilang kalo aku punya tinder, orang-orang tuh pasti bakal senyum-senyum sendiri, aku gak ngerti mereka mikir apa tapi yang jelas mungkin, aku buat ajang cari jodoh gitu. Terserah sih mereka mau mikirnya gimana, pokoknya aku emang pake itu buat hal-hal yang ga aneh-aneh" (Trica, 2017)

Adanya stigma pada pengguna Tinder membuat Trica enggan memberitahu pada banyak orang bahwa 
ia kenal pacarnya lewat Tinder. Selalu ia berbohong dan mengatakan bahwa ia dan pacarnya adalah teman kuliah atau dikenalkan oleh teman. Trica hanya mau terbuka pada teman-teman yang dekat dengannya. Bahkan kepada orang tua pun Trica juga berbohong, terlebih orangtua Trica adalah orang tua yang kolot dan sangat ketat.

"Iya. Ya mereka pada ketawa gitu. Kan selama ini mereka tu kalo kenal dari dunia nyata gitu lho, ga pernah dari sosmed. Aku selalu bilang kalau kita temen kuliah, atau aku dikenalin temenku. Kalau orang tuaku tau kita kenal di Tinder pasti deh dimarahi" (Trica, 2017)

Selain untuk mencari jodoh, bagi Trica Tinder adalah tempat untuk aktualisasi diri. Tinggal dalam rumah yang sangat mengekang membuat Trica sering kali kesusahan dalam mengekspresikan diri. Kedua orang tuanya sangat berfokus pada pendidikan sehingga Trica seringkali dilarang untuk bergaul. Apalagi kepribadian dan preferensi Trica yang sedikit unik membuatnya terkadang juga susah dimengerti oleh orang lain. Menurutnya, orang-orang di Tinder lebih terbuka dan mampu menerima dirinya dengan baik.

“Orang tuaku tuh ketat banget. Pokoknya yang dimauin tuh anaknya sekolah doang sama belajar bisnis. Apa-apa ga boleh. Mau pacaran aja juga dilarang-larang. Sedangkan di Tinder kayak bener-bener bisa bebas. Aku bisa mengekspresikan diriku, dan itu nyenengin banget." (Trica, 2017)

\subsection{Kisah Putra}

Bagi beberapa orang dan salah satunyanarasumbermenganggapaplikasi tinder menjadi sarana pencarian jodoh yang lebih praktis, instan, dan mudah digunakan. Mencari jodoh berdasarkan kecocokan yang direkomendasikan oleh aplikasi tersebut sendiri masih dianggap tabu ole masyarakat. Hal tersebut karena pada dasarnya cocok atau tidaknya dalam pencarian jodoh secara nyata terkait beberapa hal misalnya berada disuatu lingkup yang sama, perjodohan melalui orang tua, atau relasi antar hubungan pertemanan yang secara keseluruhan berdasarkan kepercayaan kepada pada agen agen yang sebagai penghubung (orang tua dan teman) terhadap kecocokan sifat dan fisik orang tersebut.

"Aku memutuskan pake tinder karena menurut yang ada di internet Tinder merupakan aplikasi pencarian jodoh yang paling bagus, user interfacenya bagus dari gambar dan cara pemakaiannya gampang. Aplikasi ini masih agak aneh menurut saya masih aneh, karena perubahan virtual kenalan lewat swipe kanan atau swipe kiri sehingga aplikasi jodoh semudah dengan menggeser jari." (Putra, 2017)

Tinder merupakan alternatif termudah untuk mencari jodoh menurut Putra. Namun seperti yang dirasakan narasumber, kecocokan (match) yang direkomendasikan Tinder terkadang saat bertemu mengalami suatu kecanggungan dan kesulitan membangun topik pembicaraan yang cocok akibat minat dan pemikiran yang berbeda bahkan 
cenderung digunakan bukan untuk mencari romantic relationship tetapi justru sex relationship. Terlebih hubungan di Tinder seringkali tidak bersifat eksklusif, sekalipun sebuah hubungan yang serius. Karena setiap orang bisa melakukan pendekatan pada banyak orang dalam sekali waktu.

"Ketika ketemu jujur tambah áwkward, karena common interest berdasarkan facebook sedangkan facebook jaman sekarang udah mati jadi kurang kuat untuk membangun topik bahasan. Apalagi seringnya di Tinder hubungan itu justru cuma berubah jadi hubungan sex aja, ya tapi I cant blame them." (Putra, 2017)

Ya wajar sih kalau di saat yang sama deketin banyak orang. Aku pernah sih ngelakuin itu cuma pada akhirnya aku kayak ngerasa bersalah. Tapi kayaknya kalau kebanyakan orang ngerasa biasa aja deh karena emang ya udah itu biasa aja di Tinder."(Putra, 2017)

Sebagai suatu yang instan, Tinder dapat menjadi alternatif untuk menemukan teman dekat untuk mengobrol yang tepat meskipun tidak mengakui secara terang terangan bahwa ia pengguna Tinder akibat stigma masyarakat bahwa pengguna Tinder merupakan orang orang yang jablay atau bisa dikatakan kesulitan mendapatkan pasangan. Pencarianjodoh untuk merujuk kesebuah hubungan yang lebih serius lagi menurut narasumber lebih cenderung berharap memperoleh hubungan secara nyata untuk membangun suatu romantic relationship dan menghindari segala stigma di masyarakat meskipun aplikasi Tinder sendiri masih tetap digunakan.

"Adalah pandangan orang pakai tinder seperti putus asa untuk mencari jodoh hingga sampai dibilang jablay. Yang tahu aku pakai Tinder cuma temen deket, agar engga ketahuan juga pake Tinder sampai ketika di tinder aku ketemu seseorang yang kemungkinan aku kenal aku langsung swipe kiri." (Putra, 2017)

Putra mengakui bahwa Tinder merupakan arena yang tepat bagi seseorang yang sudah putus asa dalam mencari pasangan. Kemudahan dalam mencari jodoh lewat Tinder serta keterbukaan dalam Tinder membuat Putra merasa bahwa aplikasi ini adalah tempat yang nyaman bagi orang-orang putus asa sepertinya.

“Orang-orang bilang kalau pake Tinder itu karena desperate. Ya, ya, gimana ya emang beneran aku desperate. Bukan karena ga laku, tapi ya cuma desperate aja cari yang simple, cuma kenapa Tinder ya karena ini paling praktis gitu buat cari temen dan pacar."(Putra, 2017)

\subsection{Tinder dan Transformasi Pemilihan Jodoh}

Berdasarkan temuandari wawancara dan observasi yang telah dilakukan, ditemukan enam poin menarik. Pertama, orang tua maupun orang lain di dalam lingkaran sosial tidak dilibatkan dalam pemilihan jodoh. Hal tersebut selaras dengan pernyataan Rosenfeld (2005) bahwa pengaruh orang tua dan orang dalam lingkaran sosial dalam pemilihan 
jodoh akan semakin berkurang sebab anak muda semakin menjauhkan diri dari keluarganya.

Temuan kedua adalah, hubungan yang tercipta di Tinder tidak eksklusif sehingga setiap orang bisa melakukan pendekatan dan menjalin hubungan dengan orang yang berbeda pada waktu bersamaan. Selain itu kerap kali hubungan tersebut diinisiasi lebih dulu oleh perempuan ketimbang lakilaki. Meskipun demikian, hal tersebut dipandang sebagai sebuah kewajaran dan perempuan tidak dipandang sebelah mata bila ia memulai hubungan terlebih dahulu. Relasi yang terjalin seolah disposable, dan pemaknaan hubungan yang demikian menjadi lumrah.

Poin ketiga, informan menjadikan Tinder sebagai ruang ekpresi dan aktualisasi diri. Jati dan Putra yang mengidentifikasikan diri sebagai demiseksual dan biseksual yang menemukan kesulitan mengekspresikan diri dengan bebas di dunia nyata merasa diterima keberadaan dan diakui identitas seksualnya dengan baik di Tinder. Sedangkan bagi Trica yang selama ini hidup dalam kekangan dan tuntutan orang tua, Tinder menjadi ruang untuk unjuk diri dan membuat keputusan yang jauh dari campur tangan orang tua. Keterbukaan Tinder terhadap keberagaman kemudian mendorong pemanfaatan Tinder sebagai sarana untuk mencari pertemanan. Ketiga informan pada awalnya menggunakan Tinder untuk mencari jodoh, namun pada akhirnya mereka juga menggunakan Tinder untuk mencari teman yang memiliki kesamaan identitas maupun ketertarikan.
Poin terakhir, keempat, pengguna Tinder mendapatkan stigma yang buruk dari masyarakat umum, Pengguna Tinder dipandang sebagai individu yang putus asa dan/atau gemar berganti-ganti pasangan seks. Stigma yang melekat membuat mereka enggan untuk secara terbuka mengakui bahwa mereka aktif menggunakan Tinder.

Temuan-temuan menarik di atas sangat relevan dengan pemikiran Manuel Castell tentang masyarakat jejaring, Peneliti mengelaborasi bahwa arus informasi yang begitu deras membuat batas sekat pemisah antara ruang oleh waktu telah hilang. Seperti yang dipaparkan oleh Castell dalam artikel jurnalnya yang berjudul Towards A Sociology of The Network Society (2000) bahwa kini masyarakat kita tengah memasuki fase masyarakat baru, dengan basis paradigma perkembangan teknologi informatika, yang mana merubah kehidupan sosial secara multidimensional. Ruang berjejaring itu semakin luas sehingga muncullah ruang baru di dalam masyarakat informasi. Dalam konteks ini Tinder telah menjadi saksi dalam transformasi sosial baik dilihat sebagai sebuah fenomena maupun sebuah jejaring baru dalam kehidupan perkembangan teknologi komunikasi.

\section{IV.SIMPULAN}

Penggunaan Tinder di kalangan muda mendorong terjadinya transformasi dalam proses pemilihan jodoh. Transformasi tersebut merupakan refleksi dari kehidupan kaum muda era modern. Proses pemilihan jodoh menjadi lebih personal, cepat, dan mudah teralihkan. Tak hanya itu, rupanya dalam konteks Indonesia Tinder juga memfasilitasi 
terbangunnya jejaring pertemanan dan mengakomodasi kaum muda dengan keberagaman identitas. Akan tetapi tak dapat dipungkiri bahwa keterlibatan teknologi dan derasnya arus informasi dalam pemilihan jodoh maupun pertemanan manusia memunculkan pertanyaan dan kegelisahan baru. Tentu fenomena ini kemudian menjadi isu yang selalu menarik sekaligus tantangan bagi persoalan manusia di era jejaring.

\section{DAFTAR PUSTAKA}

Burgess, E.S. 1978. The Family: An Introduction. Ed. Eshleman J. Ross. Boston, London, Sydney, Toronto: Allyn and Bacon, Inc.

Castell, Manuel. 2000. Towards A Sociology of The Network Society. Contemporary Sociology, Vol 29 (5): 693-699.

Castells, Manuel and Gustavo, Cardoso, eds., 2005. The Network Society: From Knowledge to Policy. Washington, DC: Johns Hopkins Center for Transatlantic Relations.

Giddens, A, 1999. Runaway World: How Globalization is Reshaping Our Lives. London. Profile.

Goode, William. J. 1991. Sosiologi Keluarga. Jakarta. Bumi Aksara.
Hurlock, Elizabeth B. 1999. Psikologi Perkembangan: Suatu Pendekatan Sepanjang Rentang Kehidupan. Jakarta. Erlangga.

Kao, Anthony. 2016. Tinder: True Love or a Nightmare? Advanced Writing: Pop Culture Intersections. Paper 16: 1-19.

Kertamukti, Rama, Heru Nugroho, Bayu Wahyono. 2019. Konstruksi Identitas melalui Stories Highlight Instagram Kalangan Kelas Menengah. Jurnal Aspikom, Vol 4 (1): 26-44.

Ningsih, Eva Yulistiana dan Pambudi Handoyo. 2015. Perjodohan di Masyarakat Bakeong Sumenep Madura: Studi Fenomenologi tentang Motif Orangtua Menjodohkan Anak. Jurnal Paradigma, Vol 3 (3): 1-5.

Proudfoot, Jenny. 2017. This is Why Everyone's Still Talking about and Using Tinder? http://www.marieclaire.co.uk/life/ sex-and-relationships/tinder-theonline-dating-app-that-everyones-talking-about-112522. diakses 5 Oktober 2017

Wismanto, Yohanes B. 2004. Kepuasan Perkawinan: Ditinjau dari Komitmen Perkawinan, Kesediaan Berkurban, Penyesuaian Diadik, Kesetaraan Pertukaran dan Persepsi terhadap Perilaku Pasangan. Disertasi. Fakultas Psikologi Universitas Gadjah Mada.

Yin, R.K. 1994. Case Study Research: Design and Methods. Thousand Oaks: Sage Publications. 